\title{
Blood vessels of human islets of Langerhans are surrounded by a double basement membrane
}

\author{
I. Virtanen • M. Banerjee • J. Palgi • O. Korsgren • \\ A. Lukinius • L.-E. Thornell • Y. Kikkawa • \\ K. Sekiguchi • M. Hukkanen • Y. T. Konttinen • \\ T. Otonkoski
}

Received: 26 November 2007 / Accepted: 11 March 2008 / Published online: 26 April 2008

(C) Springer-Verlag 2008

\begin{abstract}
Aims/hypothesis Based on mouse study findings, pancreatic islet cells are supposed to lack basement membrane (BM) and interact directly with vascular endothelial BM. Until now, the BM composition of human islets has remained elusive.

Methods Immunohistochemistry with specific monoclonal and polyclonal antibodies as well as electron microscopy were used to study BM organisation and composition in human adult islets. Isolated islet cells and function-blocking monoclonal antibodies and recombinant soluble Lutheran peptide were further used to study islet cell adhesion to
\end{abstract}

Electronic supplementary material The online version of this article (doi:10.1007/s00125-008-0997-9) contains supplementary material, which is available to authorised users.

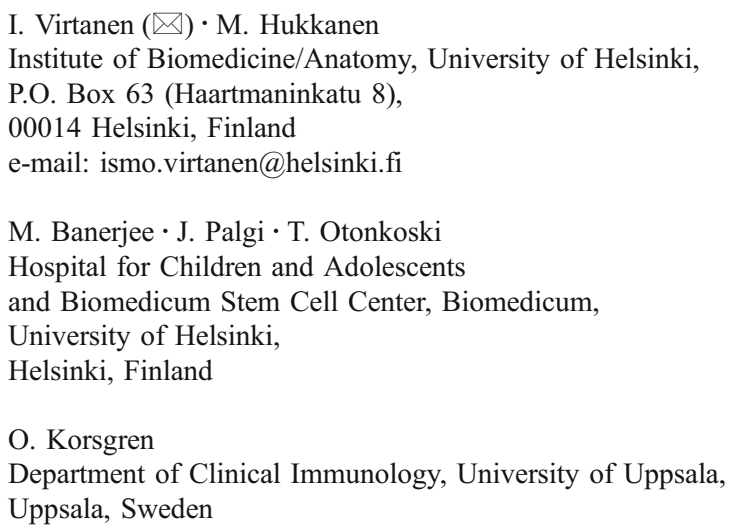

O. Korsgren

Department of Clinical Immunology, University of Uppsala, Uppsala, Sweden

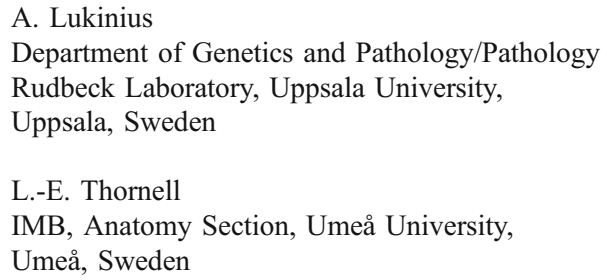

laminin (Lm)-511. Short-term cultures of islets were used to study Lutheran and integrin distribution.

Results Immunohistochemistry revealed a unique organisation for human Lm-511/521 as a peri-islet BM, which coinvaginated into islets with vessels, forming an outer endocrine BM of the intra-islet vascular channels, and was distinct from the vascular BM that additionally contained Lm-411/421. These findings were verified by electron microscopy. Lutheran glycoprotein, a receptor for the $\mathrm{Lm} \alpha 5$ chain, was found prominently on endocrine cells, as identified by immunohistochemistry and RT-PCR,

\author{
Y. Kikkawa \\ Laboratory of Clinical Biochemistry, School of Pharmacy, \\ Tokyo University of Pharmacy and Life Science, \\ Tokyo, Japan \\ K. Sekiguchi \\ Division of Protein Chemistry, Institute for Protein Research, \\ Osaka, Japan
}

Y. T. Konttinen

Department of Medicine/Invärtes medicin, University of Helsinki, Helsinki, Finland

Y. T. Konttinen

ORTON Orthopaedic Hospital of the Invalid Foundation,

Helsinki, Finland

Y. T. Konttinen

COXA Hospital for Joint Replacement,

Tampere, Finland 
whereas $\alpha_{3}$ and $\beta_{1}$ integrins were more diffusely distributed. High Lutheran content was also found on endocrine cell membranes in short-term culture of human islets. The adhesion of dispersed beta cells to Lm-511 was inhibited equally effectively by antibodies to integrin and $\alpha_{3}$ and $\beta_{1}$ subunits, and by soluble Lutheran peptide.

Conclusions/interpretation The present results disclose a hitherto unrecognised BM organisation and adhesion mechanisms in human pancreatic islets as distinct from mouse islets.

Keywords Basement membrane $\cdot$ Laminin . Langerhans islet $\cdot$ Lutheran $\cdot$ Vessels

$\begin{array}{ll}\text { Abbreviations } \\ \text { B-CAM } & \text { basal cell adhesion molecule } \\ \text { BM } & \text { basement membrane } \\ \text { CLSM } & \text { confocal laser scanning microscopy } \\ \text { ECM } & \text { extracellular matrix } \\ \text { EHS } & \text { Englebreth-Holm-Swarm } \\ \text { Lm } & \text { laminin } \\ \text { Lu } & \text { Lutheran } \\ \text { MAb } & \text { monoclonal antibody } \\ \text { PECAM-1 } & \text { platelet endothelial cell adhesion molecule-1 }\end{array}$

\section{Introduction}

Signals originating from the extracellular matrix (ECM are important for pancreatic islet development and beta cell function [1-3]. Laminin (Lm)-111 ( $\alpha 1 \beta 1 \gamma 1$ according to new Lm nomenclature [4]) plays an important role in pancreatic organogenesis [5] and differentiation of early pancreatic cells into insulin-positive beta cells [6,7], but is not present in adult mouse [8] or human pancreas [9]. In contrast, collagen IV has been found to inhibit mouse pancreatic development, while other ECM molecules like fibronectin played no apparent role [6].

Laminins, together with type IV collagens, are major basement membrane (BM) glycoproteins. Both are able to self-assemble into independent networks connected by nidogen. Laminins form a family of trimeric glycoproteins composed of an $\alpha, \beta$ and $\gamma$ chain. The Lm chains can combine into 15 different Lms, which are found in a celland tissue-specific manner $[4,10]$.

Numerous studies have suggested that BMs of most glandular organs contain Lm-332 and Lm-511, but both of these Lms are lacking in BMs of mouse pancreas, which only contain Lm-211 and Lm-411 [11, 12]. Both these studies and a recent study [13], the subject of which has been reviewed [14], suggest that the only BM found in the mouse islets is that surrounding the vascular endothelium.
In addition, Nikolova et al. [13] showed an islet capsule containing BM proteins that are not produced by endothelial cells. Some findings have indicated that in the human pancreas, endocrine cells are separated from exocrine cells by reticulin fibres [15] and the endocrine-exocrine interface in different species variably appears to contain collagens I, IV, V and VI, as well as Lm [16-18]. Electron microscopy detected [19] a typical BM facing the endocrine cell at the endocrine-exocrine interface as a peri-islet $\mathrm{BM}$, but the same study failed to detect BM inside human islets. Recent studies have provided evidence of the unique cytoarchitecture of human pancreatic islets when compared with that of rodents $[20,21]$. However, systematic studies on the BM proteins and their receptors in the human pancreas and islets are entirely lacking.

A detailed understanding of the human islet BM structure may be important for the pathogenesis of type 1 and type 2 diabetes. We have now studied BM protein composition and were able to localise them and their receptors in detail in human islets of Langerhans. Our results reveal important species differences between mice and humans.

\section{Methods}

Tissue specimens We retrieved 12 adult pancreas tissue samples obtained during surgery due to pancreatic carcinoma from the archives of the Institute of Biomedicine/ Anatomy. The specimens had been frozen in liquid nitrogen immediately after removal. Tissue sections were stained with haematoxylin-eosin to confirm their normal histology. Adult mouse pancreatic tissues were obtained from $\mathrm{Balb} / \mathrm{c}$ mice $(n=4)$ and were frozen in liquid nitrogen.

Immunofluorescence and confocal laser scanning microscopy Monoclonal antibodies (MAbs) were used for indirect immunofluorescence (Electronic supplementary material [ESM] Table 1) and bound primary antibodies visualised using AlexaFluor-488-labelled goat anti-mouse or anti-rat or anti-rabbit IgG (Invitrogen - Molecular Probes, Eugene, OR, USA). In double-labelling experiments the sections were first exposed to MAbs and their conjugates and after washing three times in phosphate-buffered saline, $\mathrm{pH}$ 7.4, exposed to polyclonal antiserum and AlexaFluor-594labelled goat anti-rabbit (Invitrogen). The specimens were embedded in veronal glycerol buffer (1:1, vol/vol., $\mathrm{pH} 8.4)$ or for confocal laser scanning microscopy (CLSM) in $90 \%$ glycerol $/ 10 \%$ (vol./vol.) veronal buffer.

The specimens were viewed with an Aristoplan (Leica, Wezlar, Germany) microscope or an AX70 Provis fluorescence microscope (Olympus, Tokyo, Japan). Images were acquired using a computer connected to a cooled digital camera mounted on the microscope. CLSM was carried out 
using a Leica TCS SP2 system with argon and krypton excitation line at 488 and $568 \mathrm{~nm}$. Image stacks were collected through the specimen using a standardised $120 \mathrm{~nm}$ z-sampling density. Selected image stacks $(n=9)$ were subjected to deconvolution and restoration using a theoretical point spread function and iterative maximum likelihood estimation algorithm (Scientific Volume Imaging, Hilversum, the Netherlands).

Transmission electron microscopy Normal pancreatic tissue from three adult patients undergoing pancreatic resection due to carcinoma was collected and small samples were immediately immersed for $6 \mathrm{~h}$ in $2 \%$ (vol./vol.) glutaraldehyde in $0.1 \mathrm{~mol} / 1$ sodium cacodylate buffer, $\mathrm{pH} 7.2$, supplemented with $0.1 \mathrm{~mol} / 1$ sucrose, and then post-fixed for $60 \mathrm{~min}$ in $1 \%$ (wt/vol.) osmium tetroxide in cacodylate buffer. The samples were then dehydrated in ethanol and embedded in Agar 100 (Agar Scientific, Stansted, Essex, UK). The ultra-thin sections were cut and contrasted with uranyl acetate and lead citrate and analysed in an H-7100 electron microscope (Hitachi, Tokyo, Japan). The islets were located by using sections stained with Toluidine Blue.

All human tissues were obtained and handled in accordance with the principles expressed in the Declaration of Helsinki and the study was approved by the local medical Ethics Committees.

Human islet isolation and short-term culture Human pancreas was processed and islets were isolated as described earlier [22] in the Central Laboratory of the Nordic Network for Clinical Islet Transplantation in Uppsala, Sweden. After Ficoll gradient purification, fractions rich in islets $(60-85 \%)$ were collected and shipped on ice to Helsinki. Informed consent was obtained for cell tissue donors and institutional Ethics Committees in Uppsala and Helsinki approved all procedures. Upon arrival, the islets were washed once with Connaught Medical Research Laboratories (CMRL) 1066 medium (Invitrogen, Carlsbad, CA, USA) and seeded on non-adherent culture dishes (Barloword Scientific, Stone, UK) in the same medium supplemented with antibiotics and 10\% FCS (PromoCell, Heidelberg, Germany). After suspension the islets, cultured for 2 to 3 days, were washed once with DMEM medium and seeded on to glass coverslips to allow attachment and partial monolayer formation. Non-adherent islets were removed on the following day and the adherent islets were allowed to form monolayers for 48 to $72 \mathrm{~h}$. Finally, the coverslips were fixed in methanol at $-20^{\circ} \mathrm{C}$ for immunoreactions.

Cell adhesion studies were performed with dissociated islet cells. For this purpose the islets were dissociated with trypsin/EDTA solution and filtered through a $70 \mu \mathrm{m}$ nylon mesh (Becton Dickinson Labware, Franklin Lakes, NJ, USA) to remove residual cell clumps. Before the experi- ment, the single cell suspension was incubated for $30 \mathrm{~min}$ at $37^{\circ} \mathrm{C}$ in a medium containing $2 \% \mathrm{FCS}$.

Cell adhesion experiments Cell adhesion was studied in 48well plates containing glass coverslips. Human Lm-511 was purified from culture medium of Jar chorioncarcinoma cells by immunoaffinity chromatography beads as described [23]. Coverslips were incubated with Lm-511 (10 $\mu \mathrm{g} / \mathrm{ml})$ at room temperature for $1 \mathrm{~h}$ and the coverslips were washed twice with PBS. The coverslips were then incubated for another hour with soluble recombinant Lutheran (Lu) (4 $\mu \mathrm{g} / \mathrm{ml}$ ) corresponding to the extracellular domain of $\mathrm{Lu}$ $[24,25]$. Single cells were counted and 8,000 to 10,000 cells were seeded on precoated coverslips in DMEM medium containing $2 \mathrm{~g} / \mathrm{l} \mathrm{BSA}$. For integrin inhibition experiments, the cells were preincubated with MAbs against integrin $\beta_{1}$ subunit (MAb 13) or $\alpha_{3}$ subunit (PIB5; Chemicon, Temecula, CA, USA). After incubation for $90 \mathrm{~min}$, the medium containing non-adhered cells was collected and the coverslips washed with PBS and fixed immediately for $15 \mathrm{~min}$ with $4 \%$ paraformaldehyde. The results are presented as the mean \pm SEM of six separate experiments, except for the integrin antibodies $(n=3)$.

RNA isolation and RT- PCR for Lu/basal cell adhesion molecule Total RNA was isolated from two different human islet preparations (purity 60 and 65\%) and cultured human corneal epithelial (HCE) cells [26] using an RNA isolation kit (NucleoSpin RNA II; Macherey-Nagel, Düren, Germany). After separate treatment with DNaseI ROQ1 RNase-free (Promega, Madison, WI, USA) and RNA cleanup with NucleoSpin RNA Clean-Up kit (Macherey-Nagel), $1 \mu \mathrm{g}$ total RNA was reverse-transcribed by M-MLVReverse Transcript-ase (Promega) in $20 \mu \mathrm{l}$ RT reaction primed by Oligo(dT)15 primer (Promega).

We used $25 \mu \mathrm{l}$ PCR containing $2 \mu \mathrm{l}$ of RT reaction as template, plus $2.5 \mu \mathrm{l} 10 \times \mathrm{PCR}$ buffer with $15 \mathrm{mmol} / 1 \mathrm{MgCl}_{2}$ (Applied Biosystems, Foster City, CA, USA), $2 \mu \mathrm{l}$ of dNuTPs mix (contains $2.5 \mathrm{mmol} / \mathrm{l}$ of each $\mathrm{dG} / \mathrm{dC} / \mathrm{dT}$ $\mathrm{dNuTP}), 4 \mu \mathrm{l}$ of the mixture of forward and reverse primers (stock of $2 \mu \mathrm{mol} / 1$ each), $2 \mu \mathrm{l}$ of $50 \%$ (vol./vol.) DMSO and $0.2 \mu \mathrm{l}$ AmpliTaq Gold $5 \mathrm{U} / \mu \mathrm{l}$ (Applied Biosystems). Polymerase activation/denaturation was performed at $95^{\circ} \mathrm{C}$ for $7 \mathrm{~min}$ and continued with 33 cycles $\left(95^{\circ} \mathrm{C} 20 \mathrm{~s}, 56^{\circ} \mathrm{C}\right.$ $\left.30 \mathrm{~s}, 72^{\circ} \mathrm{C} 30 \mathrm{~s}\right)$. The common forward primer sequence for both of the human $\mathrm{Lu}$ and basal cell adhesion molecule (BCAM) was 5'-CTACTGCGTGAGACGCAAAG-3'. The specific reverse primer for $\mathrm{Lu}$ (B-CAM variant 1) was 5'GGTCTGCTCTGGTTGCTCC-3'and for B-CAM (variant 2) 5'-GGGGATGGGGTTAAGCTATG-3'. The PCR fragments synthesised were 115 bp for Lu (B-CAM v1; NM_005581, pos. 1748-1862) and 109 bp for B-CAM (v2 NM_001013257, pos. 1748-1856). For internal control 
we used housekeeping gene cyclophilin $\mathrm{G}$ primers: forward 5'-ACTCCCAGCCTGCTTCATAC-3' and reverse 5'TACGTCTGAAACGATCCCTTG-3', fragment 126 bp (NM_004792, pos. 1161-1286). PCR (5 ml) was gelelectrophoresed in $2 \%$ agarose gel.

\section{Results}

Molecular components of the human islet basement membranes We first studied the overall distribution of Lms in the islets using an antiserum to Englebreth-Holm-Swarm (EHS)-Lm that binds to most $\mathrm{Lm}$ isoforms with the exception of Lm-332. A continuous immunoreactive line representing peri-islet $\mathrm{BM}$ and surrounding the whole islet was found (Fig. 1) and was distinct from the acinar BM of exocrine pancreas. Inside the islet, capillary BM (Fig. 1) was further surrounded by a second and distinct outer endocrine BM (Fig. 1).

The Lm chain composition of these two distinct BMs was studied using MAbs. Immunoreactivity for Lm $\alpha 1$ chain was not found (Fig. 2a). In contrast, Lm $\alpha 2$ chain showed a bright reactivity in BMs of exocrine acini, while the islet BMs lacked immunoreaction (Fig. 2b). MAb against $\mathrm{Lm} \alpha 3$ chain did not show reactivity in the islet (not shown). Immunoreactivity for $\mathrm{Lm} \alpha 4$ chain was bright in the islet blood vessel BMs (Fig. 2c), but was not detectable in the peri-islet $\mathrm{BM}$ or in the outer leaflet of the duplex BM around intra-islet vascular channels. Immunoreactivity for $\mathrm{Lm} \alpha 5$ chain surrounded the islets and acini (Fig. 2d,h). Inside the islets, immunoreactivity for $\mathrm{Lm} \alpha 5$

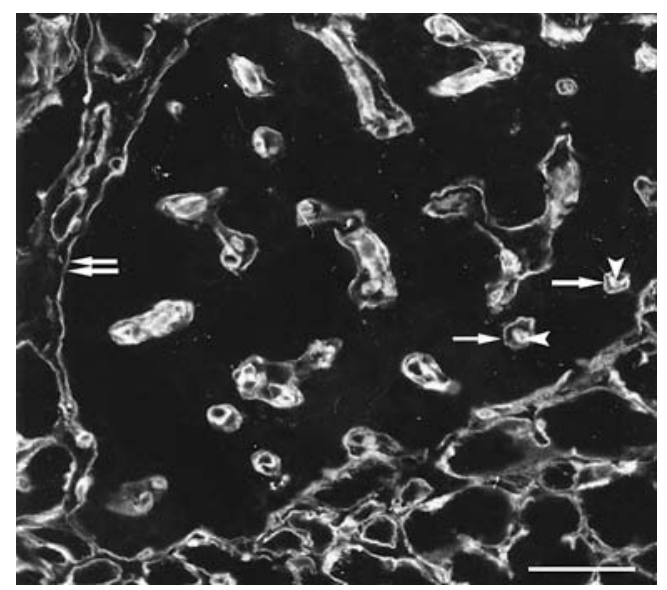

Fig. 1 Indirect immunofluorescence of human islet of Langerhans reacted with an antiserum to mouse-EHS Lm. A brightly immunofluorescent $\mathrm{BM}$ encircles the whole islet (double arrow) which is clearly distinct from the BMs of the acini of the exocrine pancreas. Intra-islet blood vessels are surrounded by a duplex BM consisting of an outer Lm-reactive parenchymal BM (arrows) that is distinct from the vessel and capillary BM (arrowheads). Bar, $50 \mu \mathrm{m}$ chain was found in duplex BMs around blood vessels, but only in regular single BMs in the exocrine pancreas. Immunoreactivity for $\mathrm{Lm} \beta 1$ chain was similarly distributed in the single-layered peri-islet, peri-acinar and parenchymal perivascular BMs and in the double-layered BMs around the intra-islet blood vessels (Fig. 2e). Immunoreactivity for $\mathrm{Lm} \beta 2$ chain was very intense, but confined to the intra-islet duplex BMs (Fig. 2f), being nearly negative in the exocrine pancreas with the exception of arterial walls feeding the intra-islet capillaries (not shown). In the high magnification picture (Fig. 2f) Lm $\beta 2$ chain-reactive inner capillary BM (arrow) was surrounded by a separate $\mathrm{Lm} \beta 2$-immunoreactive outer BM. In the pancreatic tissue, $\mathrm{Lm} \beta 3$ and $\gamma 2$ chain immunoreactivities were only found in BMs of larger ducts (not shown). Immunoreactivity for $\mathrm{Lm} \gamma 1$ chain was found in BM surrounding the islets and in the duplex BMs of the intraislet vascular channels (Fig. 2g). Larger magnification, in the example shown for the Lm $\alpha 5$ chain (Fig. 2h), clearly shows the distinction of the peri-islet BM from that of the delicate acinar BMs in the exocrine pancreas. Figure $2 \mathrm{~h}$ also clearly demonstrates a tangential section of an invaginating vessel (asterisk).

CLSM analysis of EHS-Lm immunoreactivity revealed a distinct reaction in endocrine parenchymal and capillary layers of the duplex BMs around the intra-islet vascular channels (Fig. 3a), whereas labelling with $\mathrm{Lm} \alpha 4$ chain MAb (Fig. 3b) showed immunoreactivity only in BMs of the capillaries (Fig. 3c). Figure $3 \mathrm{~d}-\mathrm{f}$ shows high-resolution confocal views of an islet capillary immunoreactive for platelet endothelial cell adhesion molecule-1 (PECAM-1) (Fig. 3d) and EHS-Lm (Fig. 3e). The merged image (Fig. 3f) shows that PECAM-1 reactive endothelium underlies the inner endothelial $\mathrm{BM}$ and that the outer parenchymal BM is distinct from it.

Since the Lm network in the BMs is connected to type IV collagen by nidogen, we also studied the distribution of collagen IV (ESM Fig. 1) and nidogen (ESM Fig. 1b) immunoreactivities. MAbs against these $\mathrm{BM}$ proteins generated a strong immunoreaction both in the outer endocrine $\mathrm{BM}$ and the inner vascular endothelial $\mathrm{BM}$, clearly exposing the double-layered nature of BM around blood vascular channels in the islets. ESM Figure 1 shows a vessel $\mathrm{BM}$ co-invaginating with the peri-islet $\mathrm{BM}$.

The aforementioned results suggest the existence of a double-layered BM organisation around the vascular channels of human islets: the inner vascular leaflet of the duplex contains Lm-411/-421 and -511/-521, whereas the outer leaflet facing the parenchymal endocrine cells contains only Lm-511. In addition, Lm-521 was seen in the outer leaflet of the vascular channel facing the parenchymal endocrine cells. To further verify this unique double-layered $\mathrm{BM}$ organisation inside the islets, electron microscopy was 

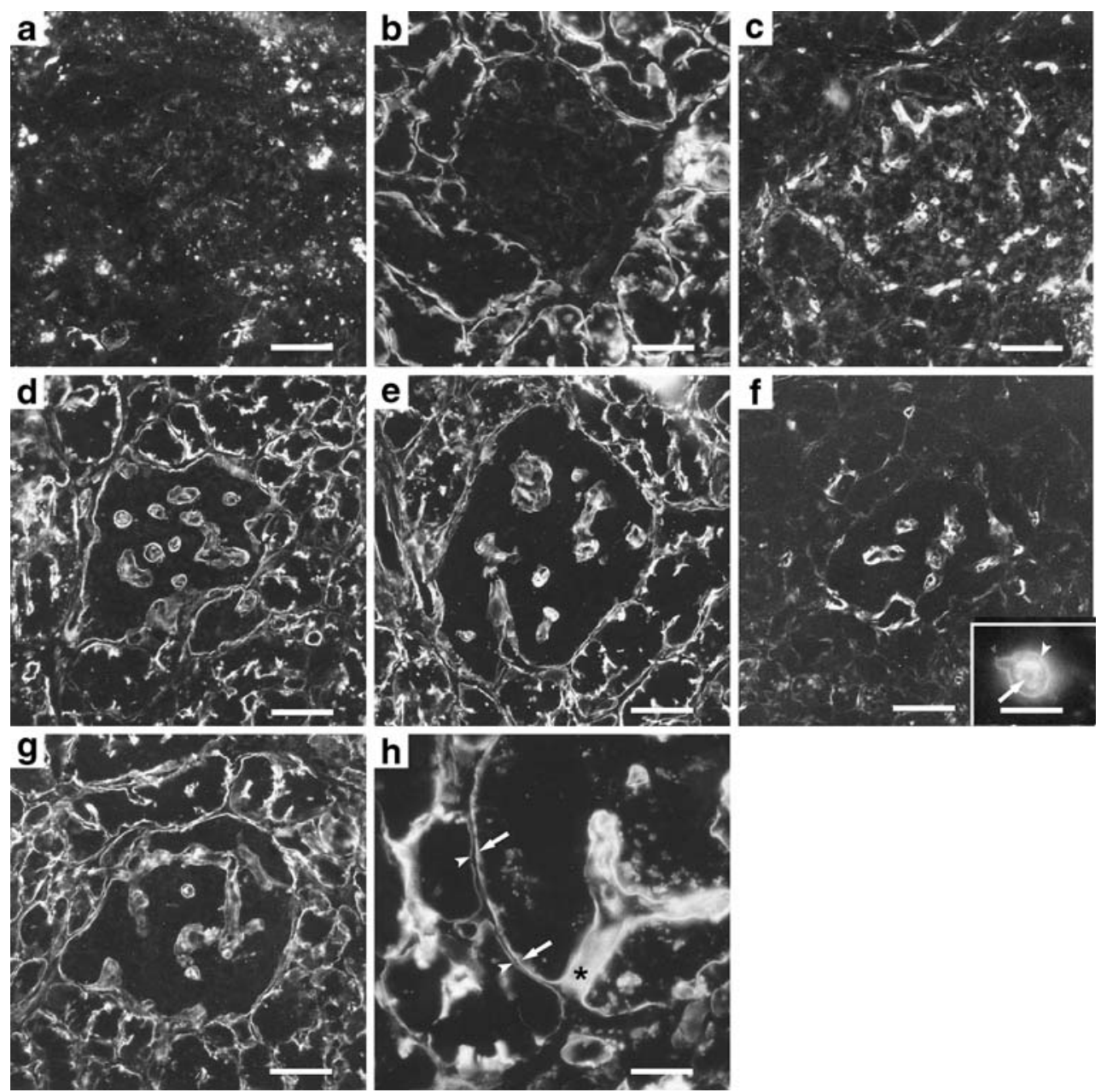

Fig. 2 Indirect immunofluorescence of human Langerhans islet with monoclonal antibodies against $\operatorname{Lm} \alpha 1$ (a), $\alpha 2$ (b), $\alpha 4$ (c), $\alpha 5$ (d, h), $\beta 1$ (e), $\beta 2$ (f) and $\gamma 1$ (g) chains. Immunoreactivity for $\operatorname{Lm} \alpha 1$ and $\alpha 2$ chains is lacking in islet tissue although $\mathrm{Lm} \alpha 2$ chain is prominent in the $\mathrm{BM}$ of the pancreatic acini (b). Immunoreactivity for $\mathrm{Lm} \alpha 4$ chain (c) is only seen in the vascular BM, in islets and in exocrine pancreas. $\mathrm{Lm} \alpha 5$ (d), $\beta 1$ (e) and $\gamma 1$ (g) immunoreactivities are seen as continuous lines around the islet and as duplex BMs around the intraislet blood vessels separating the vascular endothelial and pancreatic endocrine cells supported by the inner and outer leaflet of the duplex
$\mathrm{BM}$, respectively. $\mathrm{Lm} \beta 2$ (f) chain is prominent in vascular BMs in the islets, whereas only traces of immunoreactivity are seen in the periislet $\mathrm{BM}$ and the exocrine pancreatic tissue. Higher magnification (insert) shows more clearly the outer BM facing the endocrine cells (arrowhead) and the inner vascular BM (arrow). h At a higher magnification immunoreactivity for $\mathrm{Lm} \alpha 5$ chain is seen in $\mathrm{BM}$ surrounding the islet (arrows), which is clearly distinct from the BMs of the exocrine acini (arrowheads). Asterisk $\left(^{*}\right)(\mathbf{h})$, tangential section of a vessel invaginating into the islet tissue. Bars: $\mathbf{a}-\mathbf{g} 50 \mu \mathrm{m}$; $\mathbf{f}$ insert, $10 \mu \mathrm{m} ; \mathbf{h} 30 \mu \mathrm{m}$ used. Figure 4 shows a representative capillary in an islet. A distinct BM of the capillary endothelial cell can be seen, which is distinct from the BM of an adjacent endocrine cell (Fig. 4) and contiguous with the BM of a neighbouring endocrine cell (Fig. 4).

Laminin receptors in human islets of Langerhans Previous studies of $\mathrm{Lm}$ receptors in mouse and rat tissues have suggested that integrin $\alpha_{3}, \alpha_{6}$ and $\beta_{1}$ subunits are important for the development, organisation and function of rodent islets [2, 3, 18, 27-29]. Therefore, we studied the distribution of these and other integrin subunits as well as non-integrin $\mathrm{Lm}$ receptors in the human islet. Immunoreactivities for integrin $\beta_{1}$ (Fig. 5a) and integrin $\alpha_{3}$ subunits (Fig. 5b) were rather diffuse and found on the vascular endothelia and endocrine walls of vascular channels $\left(\alpha_{3}\right)$, but also on endocrine cells. Integrin $\alpha_{6}$ subunit in the islets was only found on vascular endothelia (Fig. 5c). No immunoreactivity for integrin $\alpha_{2}$ or $\beta_{3}$ subunits was found, while immunoreactivity for $\alpha_{\mathrm{v}}$ and $\beta_{5}$ subunits was diffuse (not shown). Some immunoreactivity for $\alpha$-dystroglycan was found in a relatively typical punctate manner on the vascular endothelial cells (Fig. 5d); it coaligned with that of $\mathrm{Lm} \alpha 5$ chain (Fig. 5e) as well as, on the outer margin of the islet, with peri-islet BM (Fig. 5d). In contrast, immunoreactivity for $\mathrm{Lu}$ glycoproteins was extremely strong, forming a continuous 

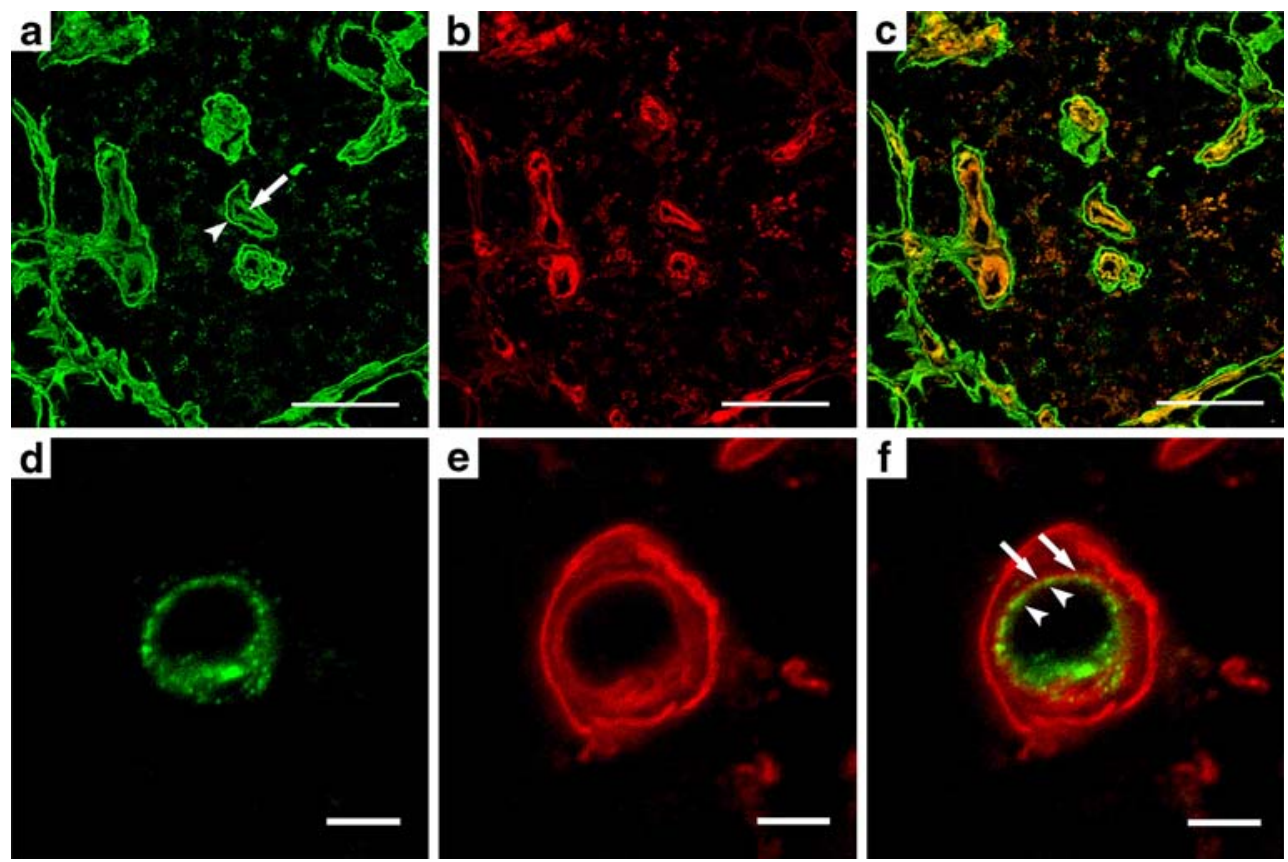

Fig. 3 CLSM of human Langerhans islets showing that the immunoreactivity for EHS Lm (a) forms BM surrounding the islet as distinct from that of the exocrine acini and a duplex BM around the blood vessel channels in the islet with a vascular inner BM sheet (arrow) distinguishable from the outer parenchymal endocrine BM (arrowhead). Immunostaining for $\operatorname{Lm} \alpha 4$ chain (b) shows reactivity only in the capillary BM as shown in orange in the merged picture (c). A double immunoreaction for PECAM-1 (d) and EHS Lm (e) shows in nine confocal sections after deconvolution that the inner vessel BM, as seen in merged figure (f) (arrow), is lined inside by PECAM1-reactive endothelium (arrowhead). Bars: a-c $30 \mu \mathrm{m}$; d-f $10 \mu \mathrm{m}$

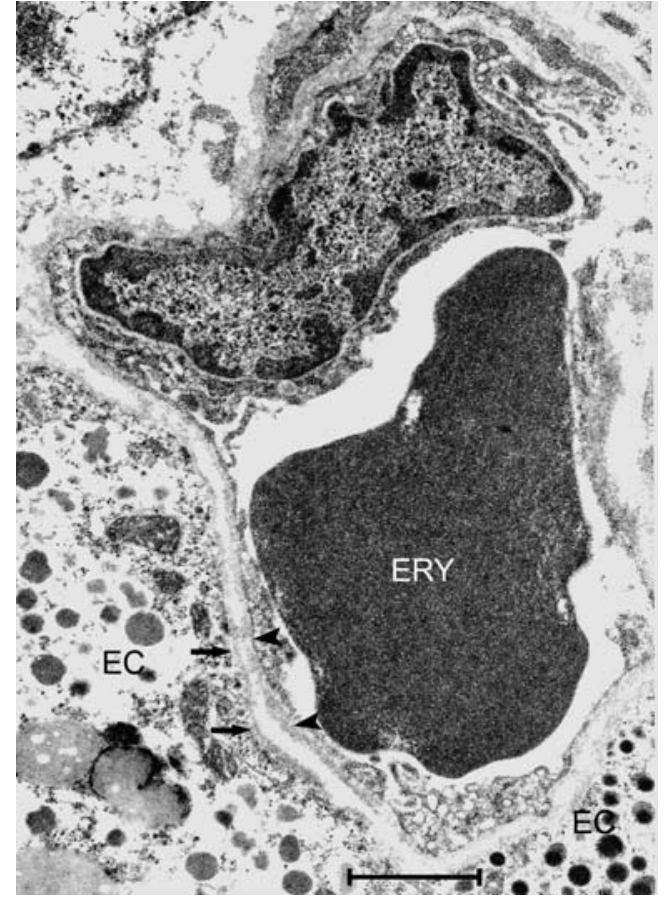

Fig. 4 Representative transmission electron microscopic (TEM) micrograph showing an erythrocyte (ERY) in a capillary blood vessel close to endocrine cells (EC). Arrowheads show the capillary BM, which is clearly distinct from BM (arrows) of the insulin- and glucagon-secreting cells. Original magnification: $\times 20,000$. Bar, $1 \mu \mathrm{m}$ polarised band at the periphery of the islet and facing the peri-islet BM, and also facing the outer parenchymal endocrine BM of the vascular channels (Fig. 5f).

Exocrine acinar cells were also immunoreactive for $\mathrm{Lu}$, but this reactivity was weaker. Double immunolabelling in CLSM using polyclonal antiserum revealed Lu (Fig. 5g) on the periphery of the islet, facing the peri-islet $\mathrm{BM}$, and on the outer leaflet of the duplex BM surrounding the intraislet vascular channels, with fainter Lu labelling of the vascular endothelial cells facing the inner leaflet of the duplex BM. Immunoreactivity for BM-confined $\mathrm{Lm} \alpha 5$ chain (Fig. 5h) was located in close coalignment with that of $\mathrm{Lu}$ on the surfaces of the endocrine cells (Fig. 5i). Double immunostaining was also used to show that integrin $\alpha_{6}$ subunit (ESM Fig. 2a) was colocalised with PECAM-1 (ESM Fig. 2b) in islets.

To show more precisely the localisation of $\mathrm{Lu}$ on islet endocrine cells, we used double immunofluorescence which showed a variable strong granular reactivity for chromogranin-A, a marker of neuroendocrine cells, in islet endocrine cells (ESM Fig. 3) and a strong polarised Luimmunoreactivity (ESM Fig. 3b) on the periphery of chromogranin-A-positive cells.

Since on the basis of differential splicing, two distinct isoforms of $\mathrm{Lu} / \mathrm{B}-\mathrm{CAM}$ are known to exist [30], we used 

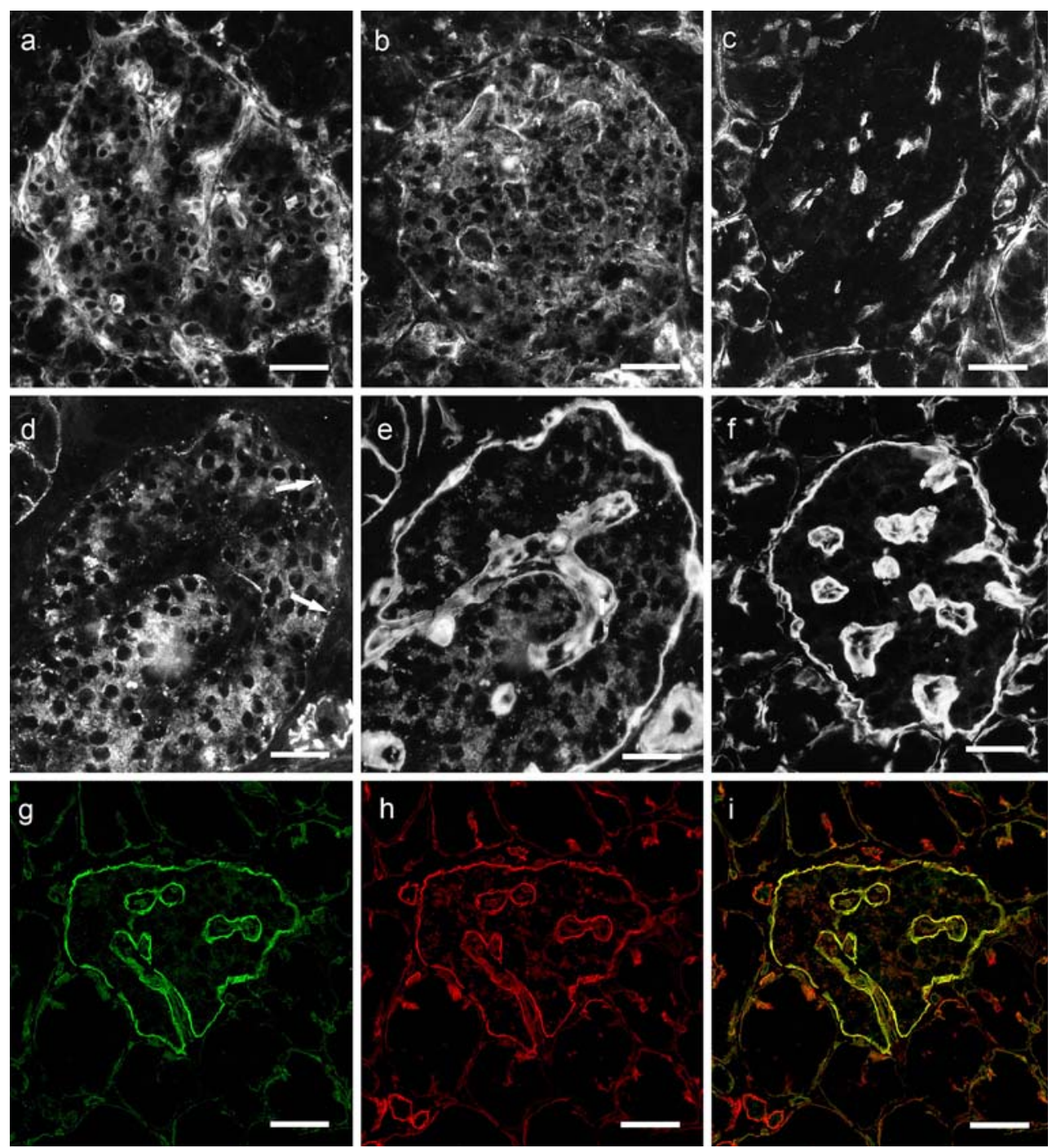

Fig. 5 Distribution of integrin and non-integrin Lm receptors in the islet. Immunoreactivity for integrin $\beta_{1}$ (a) chain is seen on endocrine islet cells and more clearly on vascular endothelia. Immunoreactivity for integrin $\alpha_{3}$ subunit (b) is similar. Immunoreactivity for integrin $\alpha_{6}$ subunit in the islets is only found on vascular endothelial cells (c). Typical punctate immunoreactivity for $\alpha$-dystroglycan (arrows) (d) is scattered on endocrine and vascular endothelial cells partially coaligning with that of the much more strongly labelled $\mathrm{Lm} \alpha 5$ chain (e). A very prominent immunoreactivity for $\mathrm{Lu}$ (f) is seen on the surface of these endocrine cells facing the exocrine pancreatic tissue in

PCR with specific primers to identify these two mRNA variants in human islets. The $5^{\prime}$-primer is common to both mRNA forms, but the $3^{\prime}$-primers are designed specifically to distinguish the 3 '-end of the Lu mRNA coding region from the mRNA of B-CAM not containing this region that codes the cytoplasmic src-homology 3 domain binding area and Ser/Thr phosphorylation sites. Positive PCR results were obtained only for transcripts of $\mathrm{Lu}$ isoform (variant 1 ), but not for the shorter B-CAM isoform (variant 2) (ESM Fig. 4).

The high content of $\mathrm{Lu}$ prompted us to study its distribution in short-term cultures of dissociated human the periphery of the islet and in those facing the vascular compartment inside the islets. Immunolabelling with polyclonal antibodies against $\mathrm{Lu}(\mathrm{g})$ shows continuous and strong immunolabelling on the surface of the endocrine cells facing the BM that surrounds the islet and coinvaginates with the invading vessel being prominent on endocrine cells that cover vascular channels. Vascular endothelial cells show a weak immunoreactivity for Lu. h Double immunoreaction for $\mathrm{Lm} \alpha 5$ chain was co-aligned with that of $\mathrm{Lu}(\mathrm{g})$ as shown also in orange in the merged picture (i). Bar, $50 \mu \mathrm{m}$

islets. The islet cells adhered and part of them started to spread within the examination period, while the endocrine cells, detected by antisera against chromogranin-A or insulin, remained roundish. In such cultures, double immunoreaction for $\mathrm{Lu}$ and chromogranin-A (ESM Fig. 5a,b) showed that the brightly chromogranin-A-reactive cells had a distinct membrane-confined Lu-immunoreaction, while the adherent cells lacking chromogranin-A remained negative (ESM Fig. 5c). Immunoreactivity for integrin $\beta_{1}$ subunit was low but detectable in chromogranin-positive endocrine cells (ESM Fig. 5d), while the non-endocrine 

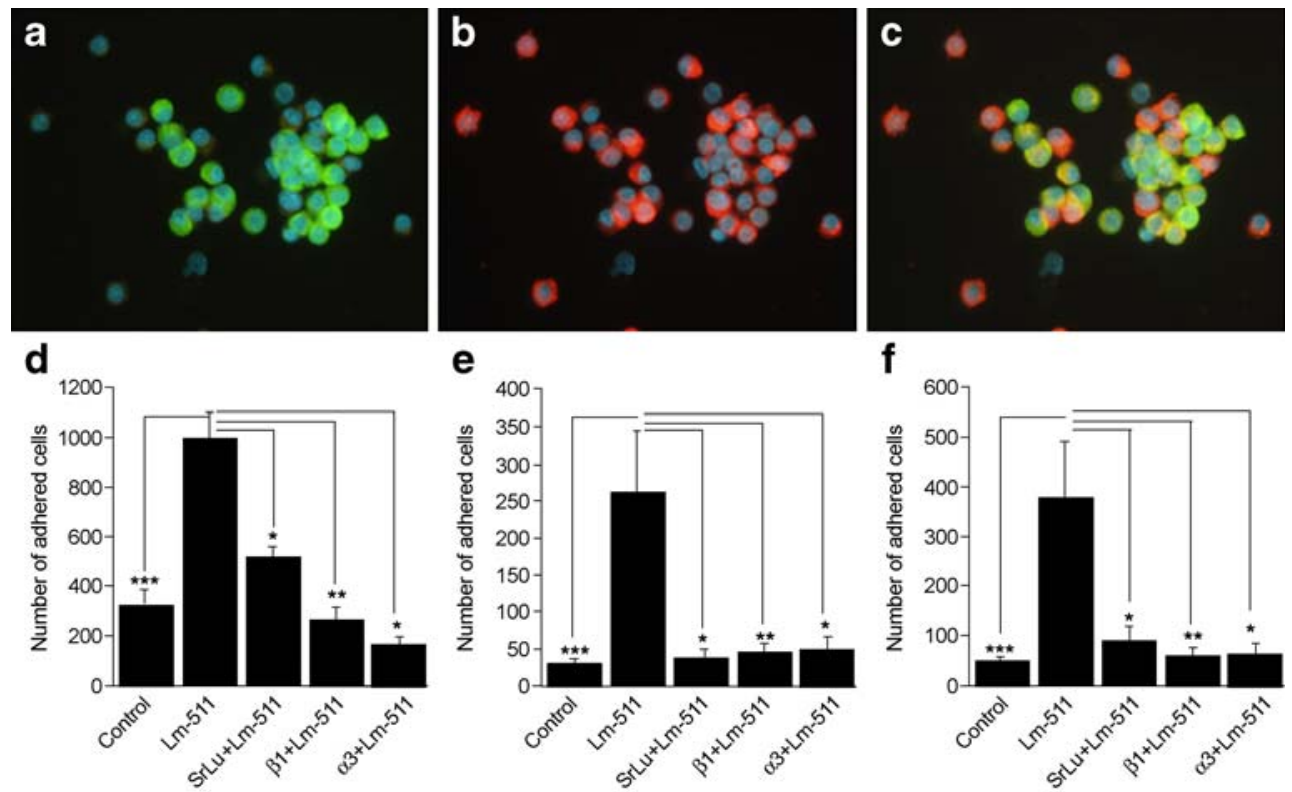

Fig. 6 Immunofluorescent images of cells double-stained for insulin (green) (a) or chromogranin A (red) (b) and both as overlay (c) after a $90 \mathrm{~min}$ adhesion experiment on Lm-511-coated substratum. Nuclear DAPI counterstaining showed that most cells were double-reactive for both antigens, while some cells (non-beta islet cells) only expressed chromogranin A. d-f Quantification of adhesion of 10000 cells per well: total cells (d); insulin-reactive cells (e); chromogranin-A-reactive cells (f). The binding to Lm-511 was inhibited by soluble Lu (SrLu) and monoclonal antibodies against integrin $\beta_{1}$ or integrin $\alpha_{3}$ subunits. The data represent the mean \pm SEM of three to six separate experiments with cells from different donors. ${ }^{*} p \leq 0.05,{ }^{* *} p \leq 0.01$ and $* * * p \leq 0.005$ for differences between groups as indicated cells showed a homogenous reaction throughout the cytoplasm and cell surface. Immunostaining for integrin $\alpha_{3}$ subunit showed a similar reaction in non-endocrine cells (not shown).

Our previous studies have shown that $\mathrm{Lu}$, either alone or together with integrin, mediates the adhesion of mesangial cells [25] and corneal epithelial cells [26] to Lm-511. We therefore studied in more detail the adhesion of dissociated islet cells on Lm-511. Short-term adhesion experiments revealed that cell substratum-coating with purified Lm-511 significantly enhanced adhesion of total islet cells, insulinpositive beta cells and chromogranin-A-positive endocrine cells. Adhesion was inhibited by preincubation with soluble $\mathrm{Lu}$ protein, this being as effective as incubation with monoclonal antibodies against $\alpha_{3}$ and $\beta_{1}$ integrin subunits (Fig. 6). Notably, soluble $\mathrm{Lu}$ inhibited the binding of insulin-positive cells much more effectively than total islet cells ( $79 \pm 4$ vs $36 \pm 5 \%$ inhibition, $n=6, p<0.001$ ).

$\alpha 5$ Lms and Lu in mouse islets of Langerhans Our results on human tissues differ distinctly from earlier mouse studies, which have shown a single-layered Lm $\alpha 5$ containing BM in the vessels of islets [11, 13] and lack of a Lm-511-containing BM in exocrine acini [12]. We therefore reinvestigated the $\mathrm{Lm}$ content of mouse islets of Langerhans using two independent new polyclonal antibodies against defined recombinant domains of mouse $\mathrm{Lm}$ $\alpha 5$ chain, domains $\alpha \mathrm{V}$ and $\alpha \mathrm{VI}$ [31]. The results show that vessels were widely labelled in the islets (Fig. 7a,b), whereas at the periphery of the islets occasional streaks of immunoreactivity were found. In line with these findings, no reactivity for $\mathrm{Lu}$ was found on endocrine islet cells, although weak vascular labelling was found in- and outside the islets (Fig. 7c).

\section{Discussion}

Several studies have suggested that ECM and/or BM proteins are required for differentiation of beta cells [3234], survival of islets in culture $[15,18]$ and enhancement of insulin production $[35,36]$. However, studies of mice have shown that there is no BM in islets of Langerhans, with the exception of vascular BM [11-14]. Therefore, in the latter studies, it was hypothesised that the vascular BM containing Lm-411 would provide a niche for insulin gene expression for beta cells. Here, we present multiple lines of evidence for a distinctly different duplex BM organisation of human islets of Langerhans.

This evidence is based on: (1) the use of a general (EHS) Lm immunoreactivity; (2) specific profiling of the Lm chain composition of the two distinctively different BMs; (3) demonstration of the duplex BM organisation using 

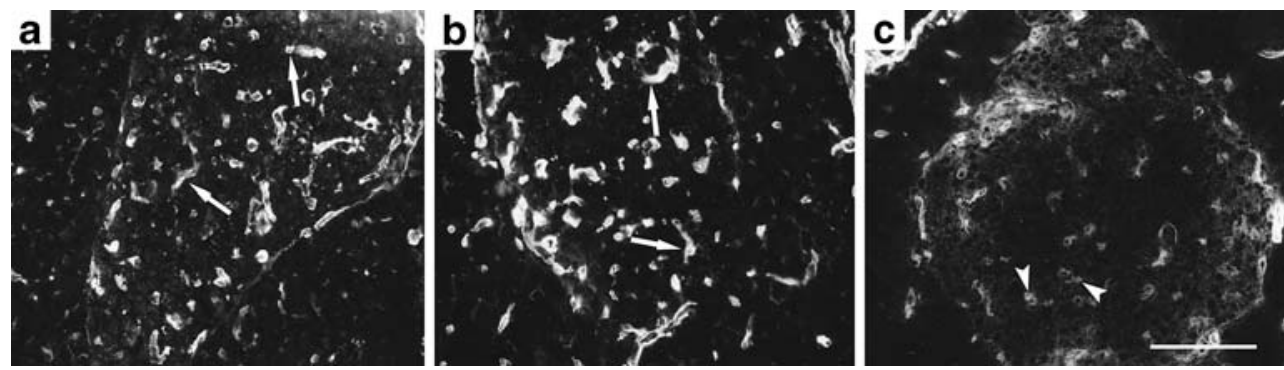

Fig. 7 The distribution of $\mathrm{Lm} \alpha 5$ chain (a, b) and $\mathrm{Lu}$ (c) immunoreactivities in mouse islets of Langerhans. Polyclonal antisera against Lm $\alpha 5$ domains VI (a) and V (b) showed that vessels in islets were widely labelled, whereas at the islet periphery occasional streaks of immunoreactivity were seen (arrows). Polyclonal antibodies against
Lu showed $\mathbf{c}$ a faint diffuse granular staining on endocrine cells and more distinct labelling of vessel endothelia (arrowheads). All three reactions indicate a lack of $\mathrm{BM}$ organisation in endocrine tissue of mouse islets of Langerhans. Bar, $10 \mu \mathrm{m}$

pattern. Remarkably, Lu was very prominent in polarised distribution in the most peripherally located islet cells, strongly suggesting that it is the major Lm-511/-521 binding receptor of endocrine cells. While only little is known about the specific functions of $\mathrm{Lu}$ [30], it has been shown that mesangial cells organise the glomerular capillaries via $\alpha 5$-Lm-Lu-integrin interactions [25], suggesting that such interactions may also function at the endocrineexocrine interface in the human pancreas. Direct evidence for the role of $\mathrm{Lu}$ in the anchorage of endocrine cells to Lm-511 has come from cell adhesion studies. Our earlier studies on $\mathrm{Lu}$ have shown that while $\mathrm{Lu}$ alone cannot mediate the adhesion of mouse mesangial cells [25], it does mediate the adhesion of human endothelial cells [38] together with integrin to Lm-511 and independently of integrins during adhesion of human corneal epithelial cells [26]. The present results show that human islet endocrine cells adhere to Lm-511 in a process inhibited efficiently by soluble $\mathrm{Lu}$, but also by $\beta_{1}$-integrins, presumably integrin $\alpha_{3} \beta_{1}$. We cannot exclude the possibility that the adhesion properties of the islet cells were modified by the 2 to 3 day culture period. In particular, this could have affected the polarised localisation of $\mathrm{Lm}$ receptors, if the cells had been separated from their natural BM. Further studies are needed to investigate preservation of the human islet BM during

\section{a}
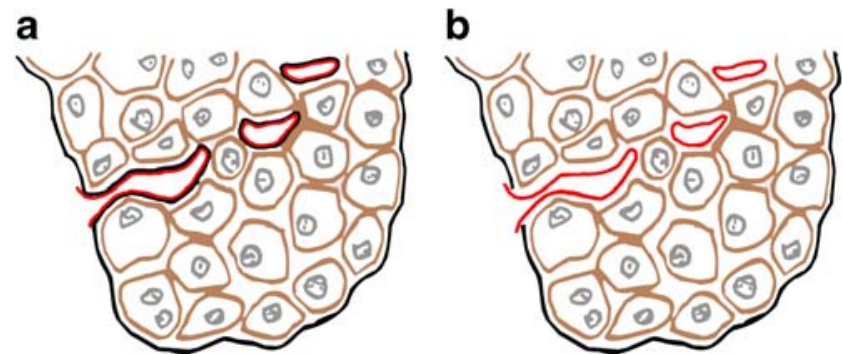

Fig. 8 A schematic view of BM organisation in human (a) and mouse (b) islets. Black line, endocrine BM, which is seen to co-invaginate with vessel BM (red) into the interior of islet. In mouse only red vessel $\mathrm{BM}$ penetrates the islet tissue apparent polarisation towards BM [37] and that immunoreactivities for dystroglycan showed a typical punctate 
islet isolation using collagenase treatment. This has potentially important implications for clinical islet transplantation.

Lm-521 is a Lm isoform found only in some specific tissues such as in kidney glomeruli, synaptic BM and walls of vessels [39]. In this respect it is interesting that we found a high content of Lm $\beta 2$ chain, a component of Lm-421 and Lm-521, in adult islet vessel BMs and also in BM adjacent to endocrine cells inside the islet.

In summary, we have shown that in clear contrast to the mouse islet, where endocrine cells are in direct contact with the vascular BM, the human islet has a unique double BM structure consisting of specifically structured and closely associated parenchymal and endothelial BMs (for schematic depiction of the BM organisation of islets of Langerhans in man and mouse, see Fig. 8). Furthermore, one of the major $\mathrm{Lm}$ receptors found on human islet cells is the $\mathrm{Lu}$ glycoprotein. These observations have potentially important implications for the ECM-mediated regulation of human islet cells, as well as for the inflammatory processes associated with insulitis.

Acknowledgements The MAb M3F7 developed by Foellmer et al. [40] was obtained from the Developmental Studies Hybridoma Bank developed under the auspices of the NICHD and maintained by The University of Iowa (Department of Biological Sciences, Iowa City, IA, USA). The skilful technical assistance of H. Kamppinen, R. Karppinen, M.-L. Piironen, O. Rauanheimo and H. Wennäkoski is acknowledged. D. Cheresh, E. Engvall, J. H. Miner, L. J. Old, P. Rousselle, T. Sasaki and L. M. Sorokin are kindly acknowledged for providing antibodies. I. Virtanen was supported by the Finnish Foundation for Diabetes Research and an EVO grant TYH6269 and T. Otonkoski was supported by the Juvenile Diabetes Research Foundation, the Academy of Finland and the European Union (STREP SAVEBETA, contract Nr. 036903 in the 6th Framework Program of the European Community). L.-E. Thornell was supported by Umeå University and the Swedish Research Council.

Duality of interest The authors declare that there is no duality of interest associated with this manuscript.

\section{References}

1. Brivanlou AH, Darnell JE Jr (2002) Signal transduction and the control of gene expression. Science 295:813-818

2. Jiang FX, Harrison LC (2002) Extracellular signals and pancreatic $\beta$-cell development: a brief review. Mol Med 8:763-770

3. Parnaud G, Hammar E, Rouiller DG, Armanet M, Halban PA, Bosco D (2006) Blockade of $\beta 1$ integrin-laminin-5 interaction affects spreading and insulin secretion of rat $\beta$-cells attached on extracellular matrix. Diabetes 55:1413-1420

4. Aumailley M, Bruckner-Tuderman L, Carter WG et al (2005) A simplified laminin nomenclature. Matrix Biol 24:326-332

5. Crisera CA, Kadison AS, Breslow GD, Maldonado TS, Longaker MT, Gittes GK (2000) Expression and role of laminin-1 in mouse pancreatic organogenesis. Diabetes 49:936-944

6. Jiang FX, Cram DS, DeAizpurua HJ, Harrison LC (1999) Laminin-1 promotes differentiation of fetal mouse pancreatic $\beta$ cells. Diabetes 48:722-730
7. Antinozzi PA, Garcia-Diaz A, Hu C, Rothman JE (2006) Functional mapping of disease susceptibility loci using cell biology. Proc Natl Acad Sci U S A 103:3698-3703

8. Falk M, Ferletta M, Forsber E, Ekblom P (1999) Restricted distribution of laminin $\alpha 1$ chain in normal adult mouse tissues. Matrix Biol 18:557-568

9. Virtanen I, Gullberg D, Rissanen J et al (2000) Laminin $\alpha 1$ chain shows a restricted distribution in epithelial basement membranes of fetal and adult human tissues. Exp Cell Res 257:298-309

10. Miner JH, Yurchenco PD (2004) Laminin functions in tissue morphogenesis. Annu Rev Cell Dev Biol 20:255-284

11. Jiang FX, Naselli G, Harrison LC (2002) Distinct distribution of laminin and its integrin receptors in the pancreas. J Histochem Cytochem 50:1625-1632

12. Miner JH, Li C, Patton PL (2004) Laminins $\alpha 2$ and $\alpha 4$ in pancreatic acinar basement membranes are required for basal receptor localization. J Histochem Cytochem 52:153-156

13. Nikolova G, Jabs N, Konstantinova I et al (2006) The vascular basement membrane: a niche for insulin gene expression and beta cell proliferation. Dev Cell 10:397-405

14. Nikolova G, Strilic B, Lammert E (2007) The vascular niche and its basement membrane. Trends Cell Biol 17:19-25

15. Wang RN, Rosenberg L (1999) Maintenance of beta-cell function and survival following islet isolation requires reestablishment of the islet-matrix relationship. J Endocrinol 163: 181-190

16. van Deijnen JHM, Van Suylichem PTR, Wolters GHJ, Van Schilfgaarde R (1994) Distribution of collagens type I, type III and type $\mathrm{V}$ in the pancreas of rat, dog, pig and man. Cell Tissue Res 277:115-121

17. Hughes SJ, Clark A, McShane P, Contractor HH, Gray DWR, Johnson PRV (2006) Characterisation of collagen VI within the islet-exocrine interface of the human pancreas: implications for clinical islet isolation? Transplantation 81:423-426

18. Pinkse GGM, Bouwman WP, Jiawan-Lalai R, Terpstra OT, Bruijn JA, de Heer E (2006) Integrin signaling via RGD peptides and anti- $\beta 1$ antibodies confers resistance to apoptosis in islets of Langerhans. Diabetes 55:312-317

19. van Deijnen JH, Hulstaert CE, Wolters GH, van Schilfgaarde R (1992) Significance of the peri-insular extracellular matrix for islet isolation from the pancreas of rat, dog. pig, and man. Cell Tissue Res 267:139-146

20. Brissova M, Fowler MJ, Nicholson WE et al (2005) Assessment of human pancreatic islet architecture and composition by laser scanning confocal microscopy. J Histochem Cytochem 53:10871097

21. Cabrera O, Berman DM, Kenyon NS, Ricordi C, Berggren PO, Caicedo A (2006) The unique cytoarchitecture of human pancreatic islets has implications for islet cell function. Proc Natl Acad Sci U S A 103:2334-2339

22. Ozmen L, Ekdahl KN, Elgue G, Larsson R, Korsgren O, Nilsson B (2002) Inhibition of thrombin abrogates the instant bloodmediated inflammatory reaction triggered by isolated human islets: possible application of the thrombin inhibitor melagatran in clinical islet transplantation. Diabetes 51:1779-1784

23. Fujiwara H, Kikkawa Y, Sanzen N, Sekiguchi K (2001) Purification and characterization of human laminin- 8 . Laminin- 8 stimulates cell adhesion and migration through $\alpha 3 \beta 1$ and $\alpha 6 \beta 1$ integrins.. J Biol Chem 276:17550-17558

24. Kikkawa Y, Moulson CL, Virtanen I, Miner JH (2002) Identification of the binding site for the Lutheran blood group glycoprotein on laminin $\alpha 5$ through expression of chimeric laminin chains in vivo. J Biol Chem 277:44864-44869

25. Kikkawa Y, Virtanen I, Miner JH (2003) Mesangial cells organize the glomerular capillaries by adhering to the $\mathrm{G}$ domain of laminin $\alpha 5$ in the glomerular basement membrane. J Cell Biol 161:187-196 
26. Hasenson S, Määttä M, Rousselle $P$ et al (2005) The immortalized human corneal epithelial cells adhere to laminin-10 by using Lutheran glycoproteins and integrin $\alpha_{3} \beta_{1}$. Exp Eye Res 81:415-421

27. Bosco D, Meda P, Halban PA, Rouiller DG (2000) Importance of cell-matrix interactions in rat islet $\beta$-cell secretion in vitro: role of $\alpha_{6} \beta_{1}$ integrin. Diabetes 49:233-243

28. Wang R, Li J, Lyte K, Yashpal NK, Fellows F, Goodyer CG (2005) Role for $\beta 1$ integrin and its associated $\alpha 3, \alpha 5$, and $\alpha 6$ subunits in development of the human fetal pancreas. Diabetes 54:2080-2089

29. Yashpal NK, Li J, Wheeler MB, Wang R (2005) Expression of $\beta 1$ integrin receptors during rat pancreas development - sites and dynamics. Endocrinology 146:1798-1807

30. Kikkawa Y, Miner JH (2005) Review: Lutheran/B-CAM: a laminin receptor on red blood cells and in various tissues. Conn Tissue Res 46:193-199

31. Garbe JHO, Göhring W, Mann K, Timpl R, Sasaki T (2002) Complete sequence, recombinant analysis and binding to laminins and sulphated ligands of the $\mathrm{N}$-terminal domains of laminin $\alpha 3 \mathrm{~B}$ and $\alpha 5$ chains. Biochem J 362:213-221

32. Jiang FX, Georges-Labouesse E, Harrison LC (2001) Regulation of laminin 1-induced pancreatic $\beta$-cell differentiation by $\alpha_{6}$ integrin and $\alpha$-dystroglycan. Mol Med 7:107-114

33. Gao R, Ustinov J, Pulkkinen MA, Lundin K, Korsgren O, Otonkoski T (2003) Characterization of endocrine progenitor cells and critical factors for their differentiation in human adult pancreatic cell culture. Diabetes 52:2007-2015

34. Cirulli V, Beattie GM, Klier G et al (2000) Expression and function of $\alpha_{v} \beta_{4}$ and $\alpha_{v} \beta_{5}$ integrins in the developing pancreas: roles in the adhesion and migration of putative endocrine progenitor cells. J Cell Biol 150:1445-1460

35. Hulinsky I, Harrington J, Cooney S, Silink M (1995) Insulin secretion and DNA synthesis of cultured islets of Langerhans are influenced by the matrix. Pancreas 11:309-314

36. Perfetti R, Henderson TE, Wang Y, Montrose-Rafizadeh C, Egan JM (1996) Insulin release and insulin mRNA levels in rat islets of Langerhans cultured on extracellular matrix. Pancreas 13:47-54

37. Wang RN, Paraskevas S, Rosenberg L (1999) Characterization of integrin expression in islets isolated from hamster, canine, porcine, and human pancreas. J Histochem Cytochem 47:499-506

38. Vainionpää N, Kikkawa Y, Lounatmaa K, Miner JH, Rousselle P, Virtanen I (2006) Laminin-10 and Lutheran blood group glycoproteins in adhesion of human endothelial cells. Am J Physiol Cell Physiol 290:C764-C775

39. Miner JH, Patton BL (1999) Laminin-11. Int J Biochem Cell Biol $31: 811-816$

40. Foellmer HG, Madri JA, Furthmayr H (1983) Methods in laboratory investigation. Monoclonal antibodies to type IV collagen: probes for the study of structure and function of basement membranes. Lab Invest 48:639-649 